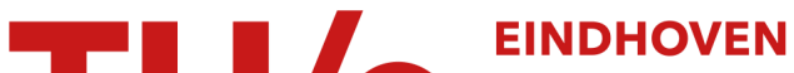 \\ UNIVERSITY OF \\ TECHNOLOGY
}

\section{The natural preference in people's appraisal of light}

Citation for published version (APA):

Haans, A. (2014). The natural preference in people's appraisal of light. Journal of Environmental Psychology, 39, 51-61. https://doi.org/10.1016/j.jenvp.2014.04.001

DOI:

10.1016/j.jenvp.2014.04.001

Document status and date:

Published: 01/01/2014

\section{Document Version:}

Publisher's PDF, also known as Version of Record (includes final page, issue and volume numbers)

\section{Please check the document version of this publication:}

-A submitted manuscript is the version of the article upon submission and before peer-review. There can be important differences between the submitted version and the official published version of record. People interested in the research are advised to contact the author for the final version of the publication, or visit the $\mathrm{DOI}$ to the publisher's website.

- The final author version and the galley proof are versions of the publication after peer review.

- The final published version features the final layout of the paper including the volume, issue and page numbers.

Link to publication

\section{General rights}

Copyright and moral rights for the publications made accessible in the public portal are retained by the authors and/or other copyright owners and it is a condition of accessing publications that users recognise and abide by the legal requirements associated with these rights.

- Users may download and print one copy of any publication from the public portal for the purpose of private study or research.

- You may not further distribute the material or use it for any profit-making activity or commercial gain

- You may freely distribute the URL identifying the publication in the public portal.

If the publication is distributed under the terms of Article 25fa of the Dutch Copyright Act, indicated by the "Taverne" license above, please follow below link for the End User Agreement:

www.tue.nl/taverne

Take down policy

If you believe that this document breaches copyright please contact us at:

openaccess@tue.nl

providing details and we will investigate your claim. 


\title{
The natural preference in people's appraisal of light
}

\author{
Antal Haans \\ Human-Technology Interaction Group, Eindhoven University of Technology (IPO 1.35), P.O. Box 513, NL-5600 MB Eindhoven, The Netherlands
}

\section{A R T I C L E I N F O}

\section{Article history:}

Available online 24 April 2014

\section{Keywords:}

Daylight

Artificial light

Natural preference

Beliefs

Office work

\begin{abstract}
A B S T R A C T
The natural preference refers to the human tendency to prefer natural substances over their synthetic counterparts, for example in the domains of food and medication. In four studies, we confirm that the natural preference is also operative in the domain of light. Study 1 confirmed that natural has a consistent meaning when people apply it to light, and that the source (e.g., daylight vs. electrical) and the transformation of the light (e.g., daylight through a blinded window) affects its naturalness. Studies 2 and 3 employed a classic forced-choice decision making paradigm. Study 2 did not confirm the natural preference hypothesis, probably because the artificial option had clear functional benefits over the natural one. Controlling for this confound, our hypothesis was confirmed in Study 3. In Study 4, three light sources were appraised in a randomized experiment. We confirmed that beliefs regarding the effects of light on health and concentration mediate the naturalness-attitude relationship; thus confirming instrumental motives behind the natural preference. Studies 2 and 4, however, suggest that the lower functionality of daylight-based systems may outweigh their perceived instrumental benefits. The weak and statistically non-significant correlations between connectedness to nature and light appraisals in Study 4 speak against an ideational basis for the natural preference as seen in earlier studies. Taken together, our studies provide evidence for a natural preference to be operative in the domain of light.
\end{abstract}

(c) 2014 Elsevier Ltd. All rights reserved.

\section{Introduction}

In an interview, the German light designer Ingo Maurer expressed his dismay regarding the European ban on the incandescent light bulb: "The incandescent light bulb, same as the sun, emits light by means of heating. In its warm glow all colors are reproduced, people look healthier, food tastes better, and one gets tired less easily. Now we are stuck to energy saving lamps and other types of synthetic light" (Hollands Diep, 2009/2010; p. 158). Interestingly, the light emitted by an incandescent light bulb is here preferred over that emitted by modern energy saving lamps as the former is regarded as less artificial than the latter. A similar preference for products that are perceived as natural exists in other domains, including food and medication. In these domains, a natural product is one that is directly taken from nature; with little to no processing, and without contagion by synthetic materials (Rozin, 2004, 2005).

The preference for natural products may in some cases lead to unfortunate decisions. For example, it may lead people to decide against vaccination by synthetic drugs, opting instead for more natural, but less effective treatments (DiBonaventura \& Chapman,

E-mail addresses: A.Haans@tue.nl, Antal@antalhaans.nl.
2008). Similarly, the natural preference may lead people to buy products that are packaged in natural materials, such as a wooden or cardboard box, because they expect these packages to have a lower impact on the environment than their more synthetic counterparts (Scholten \& Midden, 1997). Often however the opposite is true. Polyethylene bags, for example, have a lower environmental impact than cardboard boxes: The production process is cleaner, and less material is needed for polyethylene bags than for cardboard boxes. In the present studies, we will investigate whether the natural preference is also operative in people's appraisal of light as emitted by natural and electrical light sources, focusing in particular on office lighting.

In the normative decision making literature, the tendency to prefer natural products (e.g., a drug extracted from plants) when it is identical to or worse than its synthetically produced counterpart is called the naturalness bias (e.g., DiBonaventura \& Chapman, 2008). It is considered to be a cognitive bias as naturalness-based decisions are not made in a strictly rational manner. To use the label naturalness bias, however, one must assume scientific consensus that the synthetic product or substance is indeed equal to or better than the natural one. Moreover, it must be assumed that the general public has access to this knowledge. Much is known about how lighting affects our health, performance, and mood, but it would be wrong to claim that a scientific consensus exists on, for 
example, the effects of different light sources on office workers. Although the visual effects of light are rather well understood, research has just started to uncover the non-visual effects of light on, for example, health (see e.g., Boyce, 2012) and office work (see e.g., van Bommel, 2006). Moreover, most of the research on the effects of office lighting has been conducted in the laboratory, often using extreme lighting conditions (de Kort \& Smolders, 2010). In the present manuscript, we will therefore avoid the term naturalness bias, and use the more neutral term natural preference instead.

In general, two different, but arguably related, explanations for the natural preference have been raised in the literature: One ideational, the other instrumental (e.g., Li \& Chapman, 2012; Rozin et al., 2004). The instrumental explanation is that people prefer natural products and substances because they are believed, whether correctly so or not, to be functionally superior; more effective, better for our health, safer, tastier, and less damaging to the environment. Consistent with our expectation that there exists a natural preference in lighting, the scarce research on people's beliefs about light and light sources suggests that natural daylight, but also light from electrical daylight simulators, is regarded to be superior to conventional electrical light in many respects: It is better to work under, it makes people happier, and it is less detrimental to one's health (Veitch, Hine, \& Gifford, 1993; also Veitch \& Gifford, 1996). Moreover, such lighting beliefs are found to be correlated with people's preferences for, and general attitudes toward light sources, as well as with actual purchasing behavior (Beckstead \& Boyce, 1992).

The ideational explanation for the natural preference is that people prefer natural products and substances because they are morally superior to synthetic ones; superior simply because they are natural. Rozin et al. (2004) have argued that this ideational motive behind the natural preference has an evolutionary basis, referring to Wilson's (1984) notion of biophilia. Because our species was dependent on, and intertwined with nature in its evolutionary past, the biophilia hypothesis states that human beings have both an innate affiliation with, and a desire to connect with nature (Kellert \& Wilson, 1993).

In the lighting domain, a similar evolutionary argument is sometimes made when advocating a widespread use of wide and full-spectrum fluorescent lighting: Having evolved under the wide spectrum of sunlight, our visual, physiological and biochemical systems should best thrive under similar electric lighting conditions (Wurtman, 1975; Wurtman \& Neer, 1970; but see McColl \& Veitch, 2001; Veitch \& McColl, 2001). Evidence for an ideational preference for natural light may also be found, perhaps not in our evolutionary, but in our cultural heritage: Just consider the Sunlight League, and Sunlight Soap (Carter, 2007).

Some researchers have argued that the natural preference is mainly ideational, not instrumental (e.g., Rozin et al., 2004). When people were asked to choose between a natural drug extracted from plants, and one that had been synthetically produced in a laboratory, a significant proportion of individuals chose the natural option even when it was explicitly stipulated that both drugs were chemically identical (also DiBonaventura \& Chapman, 2008). Recently, however, Li and Chapman (2012) have demonstrated that people may not find it credible that the natural and the synthetic substance are indeed chemically the same. As a result, one cannot implicitly assume that the natural and the synthetic option are regarded equal in their instrumental benefits as well (e.g., equally effective and risk-free). Indeed, their participants' preference for natural over synthetic vitamin $C$ correlated positively with their suspicion about the stated chemical similarity, and with the extent to which they believed in unseen differences between the two choice options. These findings indicate that explicit statements of chemical similarity between the natural and the synthetic substance are not sufficient to rule out a possible instrumental explanation of the natural preference.

Li and Chapman (2012) further argued that ideational and instrumental motives behind the natural preference may be more closely related than previously assumed. One the one hand, a moral superiority of natural products may have led people to develop positive beliefs regarding the instrumental benefits of natural over synthetic products. On the other hand, cultural notions of natural products as healthier, more effective, safer, tastier, and less damaging to the environment than synthetic ones may have installed in people the heuristic that "natural is better" (Li \& Chapman, 2012). This heuristic may then act as a shortcut in our reasoning and decision-making processes.

One interesting, and hitherto unexplored possibility for testing more directly the role of ideational motives behind the natural preference is offered by recent advances in measuring people's connectedness to nature (Brügger, Kaiser, \& Roczen, 2011; Schultz, Shriver, Tabanico, \& Khazian, 2004). Connectedness to nature is defined as an individual's predisposition to affiliate with nature, and is thus conceptually similar to biophilia though without invocation of any evolutionary assumptions. A strong connectedness to nature is associated with biospheric rather than egocentric values (also Schultz, 2001), and with environmental concerns and conservation (also Davis, Green, \& Reed, 2009). If there is an ideational basis to the natural preference, then we may expect such preferences to be more strongly observed with people that are more closely interconnected with nature.

\subsection{Research goals}

In the present paper, we investigate whether the natural preference is also operative in people's appraisal of light. In Study 1, we investigate whether the concept of natural has a consistent meaning when people apply it to lighting. Moreover, we test a hypothesis raised by Rozin $(2005,2006)$ that what people consider to be natural is dependent on the source (e.g., the sun versus electrical lighting), and the extent of transformation of the natural substance (e.g., daylight through a clear versus a blinded window).

Of course, establishing that there exist differences in the perceived naturalness of light emitted by natural and electrical light sources does not provide evidence that the natural preference is operative in the domain of light; people should not only perceive daylight as more natural, they should also prefer it. Thus in studies 2 and 3 , we test whether people indeed have a preference for natural daylight over light emitted by a daylight simulator. In addition, we investigate the extent to which people believe in explicit statements of a physical similarity between electrical daylight simulation and light emitted by the sun. If the results support the research by Li and Chapman (2012), then the implication is that explicit statements of physical or chemical similarity are not an effective method for investigating a possible ideational basis behind the naturalness preference.

In a fourth and last study, we correlate the perceived naturalness of light emitted by various natural and electrical light sources with people's attitudes toward the application of these light sources in an office environment. At the same time, we test whether the anticipated positive relation is mediated by the degree to which people hold positive instrumental beliefs with respect to the effects of natural daylight on health, concentration, and the aesthetics of a room. Finally, we investigate whether a person's preference for natural light is related to his or her connectedness to nature. Exploring how connectedness to nature correlates with perceived naturalness, general attitudes, and instrumental beliefs may shed 
Table 1

Perceived naturalness of 11 types of light (in logits), standard errors of estimate (SE), and 95\%-confidence intervals for Study 1.

\begin{tabular}{|c|c|c|c|}
\hline Type of light & Naturalness & SE & $95 \%-\mathrm{CI}$ \\
\hline 1. Daylight entering through a hole in the wall (e.g., open window) & 5.96 & 0.35 & $5.27-6.65$ \\
\hline 2. Daylight entering through a clear window & 4.06 & 0.28 & $3.51-4.61$ \\
\hline 3. Light emitting from a daylight harvester on the roof that brings daylight into the room using mirrors & 0.89 & 0.14 & $0.62-1.16$ \\
\hline $\begin{array}{l}\text { 4. Light emitting from a daylight simulator, powered by the energy grid } \\
\text { (gray energy), that mimics daylight perfectly in all its aspects }\end{array}$ & $-0.17 \mathrm{a}$ & 0.11 & -0.39 to 0.05 \\
\hline 5. Daylight entering though a blinded or translucent window & $-0.23 \mathrm{a}$ & 0.11 & -0.45 to -0.01 \\
\hline 6. Light emitting from incandescent bulbs powered by solar panel & -0.68 & 0.10 & -0.88 to -0.48 \\
\hline 7. Light from energy saving light bulbs powered by energy grid (gray energy) & $-1.48_{\mathrm{b}}$ & 0.10 & -1.68 to -1.28 \\
\hline 8. Light emitting from incandescent bulbs powered by energy grid (gray energy) & $-1.67_{\mathrm{b}, \mathrm{c}}$ & 0.10 & -1.87 to -1.47 \\
\hline 9. Light emitting from white solid state (LED) lamps powered by energy grid (gray energy) & $-1.73_{c}$ & 0.10 & -1.93 to -1.53 \\
\hline 10. Light emitting from fluorescent (TL) tubes powered by energy grid (gray energy) & $-2.45_{d}$ & 0.11 & -2.67 to -2.23 \\
\hline 11. Light emitting from colored solid state (LED) lamps powered by energy grid (gray energy) & $-2.51_{d}$ & 0.12 & -2.75 to -2.27 \\
\hline
\end{tabular}

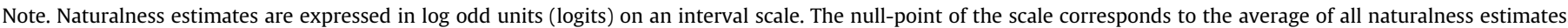

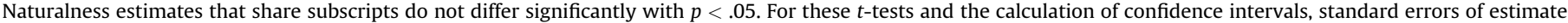

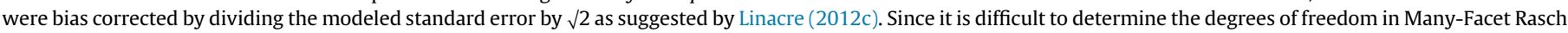
models, the number of responses minus the number of estimated parameters was used as a conservative estimate.

further light on the relation between ideational and instrumental motives behind the natural preference.

\section{Study 1}

In this first study, we test whether the concept of natural has a consistent meaning when people apply it to light. Moreover we test the hypothesis raised by Rozin $(2005,2006)$ which states that what people consider to be natural is dependent on the source, and the extent of transformation of the natural substance. We thus hypothesize that daylight is perceived as more natural than light from electrical sources, and that the substance through which daylight travels (e.g., a clear window versus are darkened window) affects its perceived naturalness. In contrast to Rozin (2005), who used a 0-100 rating scale to assess each substance's naturalness, we measure perceived naturalness by a pair-wise comparison procedure. This avoids the need to calibrate people in using a rating scale in an appropriate manner, which unavoidably tells them what the experimenter expects them to rate as, for example, natural, moderately natural, and not natural at all.

\subsection{Method}

\subsubsection{Participants}

Participants were recruited from the JF Schouten Participant Database at Eindhoven, University of Technology, Eindhoven, The Netherlands. Sixty-three persons (41 men and 22 women) participated in this study. Their mean age was $M=23.1$ ( $S D=18.1$; range 18-75). All participants received 2.00 Euro as compensation.

\subsubsection{Design \& procedure}

Participants were invited to the laboratory to evaluate light emitted from various light sources. The 11 different light types included light emitted by natural and electrical light sources, including daylight, daylight simulators, fluorescent (TL) and incandescent light sources, and solid state (LED) lighting in different colors (for the description of each light type, see Table 1). To test whether the extent of physical transformation affects perceived naturalness of light, various types of daylight were included such as daylight entering a room through an open window (no transformation), clear glass (medium transformation), mirror reflection in a daylight harvesting system (medium transformation), or a blinded window (large transformation). We also checked whether the perceived naturalness of light is influenced by the type of energy used to power its source. For this purpose, we included two descriptions of an incandescent light source: one powered by a solar panel, the other by a "gray" energy grid (i.e., supplying energy from nonrenewable sources).

Each participant compared the 11 different types of light with regard to perceived naturalness using forced-choice pair-wise comparisons. With each comparison, descriptions of two different types of light were displayed on a computer screen: one on the left, the other on the right-hand side of the screen. The E-Prime 2.1 software (Psychology Software Tools, Pittsburgh, PA) was used for presenting the light type descriptions, and for recording responses. Each participant completed all of the 55 possible comparisons. The order in which the pairs were presented, and the location of the respective alternatives on the screen was randomized across participants. With each comparison, participants were asked to select, using a computer mouse, which type of light they regarded to be the more natural of the two. The comparisons took about $10 \mathrm{~min}$ to complete.

Responses were analyzed with the many-facet Rasch model (for more details see Bond \& Fox, 2007; Linacre, 2002):

$\ln \left(\frac{p\left(x_{a b}=1\right)}{1-p\left(x_{a b}=1\right)}\right)=\delta_{a}-\delta_{b}$

In this model, the natural logarithm of the odds of choosing the first $(a)$ over the second of the pair $(b)$ is governed by the difference in the estimated naturalness of the light emitted by the first $\left(\delta_{a}\right)$ and second source $\left(\delta_{b}\right)$. If both types of lighting are equally natural (i.e., $\delta_{a}=\delta_{b}$ ), then an individual has a $50 \%$ change of choosing the first type of light over the second. This probability increases, or decreases, with an increasing difference between the two estimates. The Rasch model test was performed using the Facets software (Linacre, 2012a). The Facets software employs a joint maximum likelihood procedure to estimate the naturalness of each type of light (the $\delta \mathrm{s}$ ). Estimates are expressed in log odd units (also called logits) on an interval scale. The null-point of the scale corresponds to the average of all naturalness estimates.

With regard to data-to-model fit, we examined Mean Square (MS) fit statistics. All 11 types of light fitted the Rasch model with $M S$-values smaller than 1.20 . These values reflect the relative discrepancy in variation between model prediction and observed data. For assessing fit, MS-values up to 1.20 are considered good, and MS-values below 1.50 are considered acceptable (Wright \& Linacre, 1994).

Additionally, we examined the standardized fit statistics of each of our participants' responses to the 55 comparisons to obtain an estimate of the consensus amongst them (see Linacre, 2012c). For 10 out of 63 participants (i.e., $15.9 \%$ ), the data did not fit the model 
prediction as indicated by $t$-values of $t \geq 1$.96. In other words, there was consensus with regard to the meaning of the term natural in the lighting domain amongst a considerable $85.5 \%$ of our participants.

\subsection{Results E discussion}

The naturalness estimates for each of the 11 types of light are provided in Table 1 . We found significant differences between most pairs of light types, with $p<.05$ (see Table 1 ). Sunlight entering through an open window was regarded as the most natural of all 11 types of light. As expected, the medium through which sunlight passes significantly affects its perceived naturalness: When entering a room through clear glass, or more so for blinded or translucent glass, it was considered to be less natural than when entering through an open window. Collecting daylight using a mirror-based harvesting system was regarded to yield light that is more natural than sunlight through a blinded window, but less natural than sunlight through clear glass. This demonstrates that physical transformation of daylight decreases its perceived naturalness, thus confirming the research by Rozin (2005).

Sunlight, however it entered a room, was considered more natural than light emitted by electrical light sources, except for the daylight simulator which was regarded to emit light about as natural as sunlight through blinded glass. Of the electrical light sources, our participants regarded the incandescent light bulb as emitting the most natural light, at least when powered by a solar panel. The fluorescent (TL) tubes and colored solid state (LED) lamps were regarded to emit the least natural light.

Remarkably, the type of energy used to power an electrical light source significantly affected perceived naturalness: Light emitted from an incandescent light bulb was regarded as significantly more natural when powered through solar panels, than when powered through non-sustainable means. It seems that our participants, when making their naturalness judgment, focused not only on the emitted light, but took into account the specifics of the light source as well. Nevertheless, the results of Study 1 confirm that the concept natural has a consistent meaning in people's appraisal of light and light sources.

\section{Study 2}

Although the results of Study 1 are largely consistent with the natural preference hypothesis, establishing that there exist differences in the perceived naturalness of daylight and electrical light does not provide sufficient evidence that the natural preference is also operative in the domain of light. According to the natural preference hypothesis people should not only perceive daylight as more natural, they should also prefer it. In this second study, we employ a standard paradigm from the decision-making literature on the natural preference (e.g., DiBonaventura \& Chapman, 2008). We provide individuals with two choice options: a natural daylight option, and an artificial option that emits light that is stated to be identical to daylight in all its aspects. If a natural preference exists in the domain of light, then a greater proportion of participants will choose the natural option.

\subsection{Method}

\subsubsection{Participants}

Participants were recruited from the participant database of the Virtual Lab at Eindhoven University of Technology, Eindhoven, The Netherlands. One-hundred persons were invited to complete an online questionnaire. Seventy-six of them (33 men and 43 women) completed the survey. Their mean age was $M=29.5$ ( $S D=8.6$; range 16-63). All participants received 1.00 Euro as compensation.

\subsubsection{Design and procedure}

Each participant completed an online questionnaire consisting of three items. First, participants were instructed to read carefully the descriptions of two rooms and to select the room (A or B) they preferred most:

"Room A is lit up with light from a daylight harvester. This is a device on the roof which collects the sunlight and transfers it into the room using mirrors."

"Room B is lit up with light from a daylight simulator. This is a ceiling lamp (powered with electricity from a solar panel) that mimics daylight perfectly in all its aspects."

In making their choice, participants were instructed to focus on the quality of the light in the room, and to ignore the specifics of the luminaire (e.g., costs or energy consumption). Based on the results of Study 1, we nevertheless explicitly stated that the electrical light source was powered by solar panels. We decided to use light emitted by a daylight harvester as the natural option, rather than for example daylight entering directly to a window, to avoid the possible confound that having an outside view may have had on our participants' choices. The order of the rooms, and thus the labeling of the rooms, was counterbalanced across participants.

With a second, open format question, we asked participants to reflect on why they chose a particular room (i.e., A or B). Although such free responses may not necessarily capture the actual motives behind people's choices (see Rozin et al., 2004), we agree with Li and Chapman (2012) that they may still be informative with respect to the underlying thought processes. All but three of the 76 participants answered this question. Responses were categorized by an experimenter, who was blind to the individuals' choice of rooms. Three main themes, or categories, were identified: naturalness-related reasons, practical reasons, and comments indicating that people did not fully understand daylight harvesting. Responses were then categorized by another experimenter. Inter-rater reliabilities (Phi coefficients) were $\varphi=.92$ for the naturalness, $\varphi=.80$ for the functional, and $\varphi=.61$ for the misunderstanding category. Differences between the two experimenters' categorizations were discussed and any discrepancies were resolved. Sixty-five of the 73 responses to this open-format question (i.e., 89\%) could be classified with one or more of these themes.

With a third question, we assessed the extent to which our participants believed it credible that an electrical light source can emit light identical to daylight. For this purpose, participants were asked to read carefully the following text: "Eindhoven University of Technology has developed a new type of luminaire. This ceiling luminaire is powered with electricity from a solar panel. The researchers claim that the light emitted by this ceiling lamp is exactly identical to daylight, in all its aspects. This new ceiling lamp also mimics the natural occurring changes in daylight throughout the day, similar to a window. However, this luminaire can also be used in rooms or situations where a regular window is not possible." Subsequently, participants were asked to indicate how strongly they believed in the researchers' claim on a 10-point scale ranging from 1 (not at all credible) to 10 (absolutely credible).

\subsection{Results and discussion}

Contrary to our expectations, we did not find a clear preference for light emitted by the daylight harvester (i.e., 57\%) over light emitted by the daylight simulator, with $p=.30$ (Binomial test). In other words, we did not find the expected natural preference in people's appraisal of light. 
Moreover, our participants did not strongly believe in the daylight simulator to emit light that is identical to natural daylight, with an average credibility of $M=6.1(S D=1.7)$. This confirms the findings by Li and Chapman (2012). However, the perceived credibility of daylight simulation was not found to correlate with an individual's choice of rooms, with $r_{p t \text {-biserial }}=0.08$ and $p=.50$.

Our participants' comments on why they chose a particular room proved insightful as to why the expected natural preference was not observed. In total, $56.6 \%$ of the participants gave a naturalness-related reason for selecting a particular room. Typical such comments were "Rather real sunlight, than something that mimics it," or "The daylight harvester provides pure sunlight, not simulated sunlight." One participant commented on the perceived instrumental benefits of daylight: "Daylight is supposed to make you happier." A considerable $21.1 \%$ of the comments included practical reasons, such as "With the simulator, one is not $100 \%$ dependent on the sun," or "A daylight simulator also works during the evening." Finally, $14.5 \%$ of the comments reflected that participant did not fully understand the daylight harvesting: "I cannot imagine a room full of mirrors," or "Mirrors that reflect sunlight will be too bright." Taken together, these comments indicate that a natural preference may exist in people's appraisal of light, but that functional aspects of the lighting and a misunderstanding of daylight harvesting may have confounded the results. Therefore, we repeated Study 2 with slight changes to the questions.

\section{Study 3}

In this third study, we once more test whether a natural preference exists in people's appraisal of natural and electrical light using the classical decision-making paradigm employed in Study 2. However, we improved the survey in several ways. To avoid any misunderstandings with our participants regarding what a daylight harvester looks like, we changed our description of daylight harvesting from using mirrors as a means of transporting the light to using glass fiber. Also, we included a photograph of a regular ceiling luminaire as an illustration. Secondly, we aimed to avoid a possible confounding effect of the lesser functionality of an exclusively daylight-based system, by giving people the option between two rooms in which daylight and electrical light were mixed in different proportions.

\subsection{Method}

\subsubsection{Participants}

Participants were again recruited from the participant database of the Virtual Lab at Eindhoven University of Technology, Eindhoven, The Netherlands. One-hundred persons were invited to complete an online questionnaire. None of these persons had participated in Study 2. Seventy-seven persons (39 men and 38 women) completed the survey; 39 of which were men. Their mean age was $M=28.4$ ( $S D=6.7$; range $20-54)$. All participants received 1.00 Euro as compensation.

\subsubsection{Design and procedure}

The online survey again consisted of three items. First, participants were instructed to read carefully the descriptions of the two rooms and to select the room (A or B) they preferred most. The descriptions of the rooms were different from those used in Study 2:

"Room A: of the total amount of light during a day:

- $80 \%$ is extracted using a so-called daylight harvester on the roof, which collects daylight and transfers it into the room using glass fiber.
- $20 \%$ is generated with a daylight-simulator (powered with electricity from a solar panel) that mimics daylight perfectly in all its aspects."

"Room B: of the total amount of light during a day:

- $80 \%$ is generated with a daylight-simulator (powered with electricity from a solar panel) that mimics daylight perfectly in all its aspects.

- $20 \%$ is extracted using a so-called daylight harvester on the roof, which collects daylight and transfers it into the room using glass fiber."

The instructions were similar to Study 2, but we stated explicitly that the total amount of illumination was similar for both rooms. We also included an image of what the ceilings luminaires in the rooms look like. For this purpose, we used an image of a Cooper Sentience luminaire: a 600 by $600 \mathrm{~mm}$, completely diffuse luminaire shown recessed in a suspended ceiling system. In the remainder of the article we will call room A the daylight harvester room, and room B the daylight simulator room.

The remainder of the questionnaire and the classification procedure for the answers to the open-format question were similar to Study 2. This time, inter-rater reliabilities were $\varphi=.78$ for the naturalness, $\varphi=.74$ for the functional category. No inter-rater reliability could be calculated for the misunderstanding category as only a single response was categorized as such by one of the experimenters.

\subsection{Results and discussion}

Consistent with our natural preference hypothesis, a larger proportion of participants preferred the daylight harvester (69\%) over the daylight simulator room, with $p<.01$ (Binomial test). As before, most (50.6\%) of the people stated naturalness-related reasons for choosing one room over the other. This time, only $6.5 \%$ of the responses were categorized as reflecting practical reasons, and only one answer was categorized as reflecting a misunderstanding of daylight harvesting.

In contrast to existing research employing this paradigm (e.g., DiBonaventura \& Chapman, 2008; Li \& Chapman, 2012), we stated the light emitted by the simulator to be similar, not with the light from the daylight harvester specifically (i.e., the other choice option), but with daylight in general. This however, does not affect the interpretation of the results: Consistent with the natural preference hypothesis, people not only regarded the light from a daylight harvester to be more natural than that emitted by a daylight simulator-as found in Study 1,- but they also preferred it.

As in Study 2, our participants, on average, only moderately believed that a daylight simulator could emit light that is identical to sunlight, with $M=5.7(S D=2.0)$. This time, we found a small to moderate negative correlation between perceived credibility of daylight simulation and a preference for the more natural choice option, with $r_{p t-b i s e r i a l}=-0.29$ and $p<.01$. Our results thus confirm Li and Chapman's (2012) claim that explicit statements of similarity between a natural option and its synthetic counterpart are deemed implausible; thus supporting, by inference, their claim that such statements cannot rule out an instrumental explanation of the natural preference. In the next study, we investigate the role of instrumental and ideational motives behind the natural preference in an alternative way.

\section{Study 4}

In this fourth and final study, we test the natural preference hypothesis by correlating the perceived naturalness of light emitted 
by various natural and electrical light sources, and people's attitudes toward the application of these light sources in an office environment.

As a second goal, we investigate possible instrumental and ideational motives behind the natural preference in the domain of light. For this purpose, we conduct a series of mediation analyses to determine whether instrumental beliefs with respect to the effects of natural light on health, concentration, and the aesthetics of a room (e.g., color rendering) can mediate, or explain, part of the anticipated naturalness-attitude relationship. Second, we explore a novel way of testing the ideational explanation of the natural preference by correlating a person's connectedness to nature with his or her light appraisals. If there is an ideational basis to the natural preference, then it should be more pronounced with people that are more closely interconnected with nature.

\subsection{Method}

\subsubsection{Participants}

A convenience sample of two-hundred and sixteen persons completed an online questionnaire. Participants were recruited from various online fora, and the JF Schouten Participant Database of Eindhoven University of Technology, Eindhoven, The Netherlands. We excluded 9 participants from the analyses, because of missing values. Missing two or more responses on a single attribute (i.e., general attitude, perceived naturalness, or a light belief), reliable estimates could not be estimated for these individuals. Of the remaining 207 participants, 112 (i.e., 54.1\%) were men and 95 (45.9\%) were women. Their mean age was $M=33.8$ $(S D=16.9$; range $15-82)$. As compensation, participants could enter a raffle with ten 10.00 Euro gift certificates as prizes.

\subsubsection{Design and procedure}

We used a between-subject design to compare people's appraisals of light emitted from three different light sources that we expected to differ in their perceived naturalness based on the results of Study 1: daylight through a window in the ceiling (i.e., a skylight; $n=71)$, light emitted by a daylight simulator $(n=63)$, and light emitted by fluorescent tubes (or as abbreviated from its French name tube luminescent, TL lighting; $n=73$ ). Participants were randomly assigned to one of the three types of lighting, which they subsequently evaluated for use in an office environment using an online survey.

First, participants were asked to read carefully the description of the light source. For the daylight condition this description read: "An office workplace is illuminated by sunlight through a skylight. The glass in this skylight is frosted, causing the light to be distributed equally across the room, and minimizing glare". For the daylight simulator condition the description read: "An office workplace is illuminated by a daylight simulation system; the light emitted by this electrical light source is indistinguishable from daylight (through a frosted skylight). The light is equal to daylight in all its dimensions. The fitting's glass is frosted causing the light to be distributed equally across the room, and minimizing glare. This daylight simulator is powered by sustainable energy generated by solar panels". The description for the fluorescent lighting condition read: "An office workplace is illuminated by fluorescent (TL) lighting. The fitting's glass is frosted causing the light to be distributed equally across the room, and minimizing glare. This fluorescent lighting is powered by sustainable energy generated by solar panels".

By comparing diffuse rather than clear skylights and luminaires, we aimed to control for a possible confounding effect of having a view on the outside through the ceiling window. As in Studies 2 and 3 , we explicitly included in our descriptions that the electrical light sources were powered by solar panels. This way, we aimed to reduce possible confounds due to differences in the perceived ecological impact of the three light sources.

After reading the description, participants answered several questions assessing their general attitude toward the application of the light source in an office environment, the perceived naturalness of the light emitted by the light source, and their beliefs about its effects on their health and concentration, as well as on the aesthetics of the office room (i.e., color rendering). We also asked participants to express their beliefs with respect to the ecological impact of the light source. Ecological impact was included in this study as a control variable.

The description of the light source remained on the computer display until the participant had answered all questions. Participants answered the questions regarding their general attitude toward the light source first. Subsequently, the remainders of the questions were presented in a randomized order, but the same order was used with all participants. Finally, our participants completed a questionnaire to assess their connectedness to nature.

\subsubsection{Measures}

General attitude toward the light source was assessed with three items, such as "Is this lighting suitable or unsuitable for an office environment?" (For a description of all items, see Table 2). Perceived naturalness of the light emitted by the light source was also assessed with three items, such as "To what extent would you describe this light as natural or unnatural?" The four lighting beliefs (e.g., with respect to ecological impact, health and concentration effects, and aesthetics of the room) were also each assessed with three items. One question tapping into an individual's beliefs with respect to the light's effect on concentration, for example, read: "Do you think this type of light will have a positive or negative effect on your concentration?"

Participants could respond to each item on a 7-point scale ranging from -3 (e.g., very positive), through 0 (e.g., neutral), to 3 (e.g., very negative). Before subsequent analyses, all items were recoded so that a high score reflected more positive attitudes and beliefs, and a smaller ecological impact. Across all items, and all participants, there were 18 (i.e., 0.48\%) missing responses.

We confirmed that each item tapped into the anticipated latent variable by means of Common Factor analysis. For this purpose, we extracted six factors using Principal Axis Factoring. The factor matrix was rotated using oblique rotation (i.e., Direct Oblimin). The obtained factor solution confirmed our expectations, with each item loading on the anticipated latent variable with reasonable factor loadings of $\lambda \geq .49$ (see Table 2). Moreover, there were no cross-loadings above $\lambda=.30$. In other words, the six attributes of interest were, although correlated, empirically dissociable. Together, the six factors accounted for $74.3 \%$ of the observed variance in the data. Subsequently, we estimated factor scores by calculating, for each participant, the average response across each set of three items (i.e., the summated scale method). The correlations between the six measures are provided in Table 3. The reliability (i.e., Cronbach's alpha) of each of the six measures was high with $\alpha \geq .78$ (see Table 3 ).

Connectedness to nature was assessed with the Disposition to Connect with Nature (DCN) scale (Brügger et al., 2011). Based on Campbell's paradigm (Kaiser, Byrka, \& Hartig, 2010), the DCN estimates a person's connectedness to nature from his or her selfreported behavior and appraisals of nature. In contrast to other connectedness to other measures, it does not rely on introspections regarding one's bond with nature. Such introspections are problematic as the extent to which one is connected to nature may not be consciously available to the individual (Schultz et al., 2004). It is 
Table 2

Factors structure of the general attitude and lighting beliefs items for Study 4 .

\begin{tabular}{|c|c|c|c|c|c|c|}
\hline \multirow[t]{2}{*}{ Items } & \multicolumn{6}{|l|}{ Factors } \\
\hline & Naturalness & Eco-impact & Concentration & Health & Aesthetics & General attitude \\
\hline How natural or unnatural is this type of light? & .92 & & & & & \\
\hline To what extent would you describe this light as natural or unnatural? & .89 & & & & & \\
\hline Do you think light from this source to be natural or unnatural? & .60 & & & & & \\
\hline Do you think this type of lighting to be clean or polluting? & & .92 & & & & \\
\hline How good or bad is this type of lighting for the environment? & & .88 & & & & \\
\hline Is this type of light, to your opinion, damaging or not damaging to nature? & & .76 & & & & \\
\hline $\begin{array}{l}\text { To what extent do you think this light will } \\
\text { improve or deteriorate your concentration level? }\end{array}$ & & & .80 & & & \\
\hline $\begin{array}{l}\text { How good or poor do you think your attention } \\
\text { to work will be in this type of lighting? }\end{array}$ & & & .77 & & & \\
\hline $\begin{array}{l}\text { Do you think this type of light will have a positive or } \\
\text { negative effect on your concentration? }\end{array}$ & & & .65 & & & \\
\hline Do you think this type of lighting will improve or deteriorate your health? & & & & .81 & & \\
\hline $\begin{array}{l}\text { How positively or negatively do you think your health } \\
\text { will be influenced by this type lighting? }\end{array}$ & & & & .76 & & \\
\hline How good or bad do you think this type of lighting is for your health? & & & & .57 & & \\
\hline How beautiful or ugly do you think people will look like with this light source? & & & & & .81 & \\
\hline $\begin{array}{l}\text { How beautiful or ugly do you think printed matter } \\
\text { will look like with this light source? }\end{array}$ & & & & & .51 & \\
\hline $\begin{array}{l}\text { How beautiful or ugly do you think your work space } \\
\text { will look like with this light source? }\end{array}$ & & & & & .49 & \\
\hline Is this lighting suitable or unsuitable for an office environment? & & & & & & .93 \\
\hline Do you think this to be good or bad lighting for a workplace? & & & & & & .91 \\
\hline $\begin{array}{l}\text { How positively or negatively do you value this type of } \\
\text { lighting for an office environment? }\end{array}$ & & & & & & .73 \\
\hline
\end{tabular}

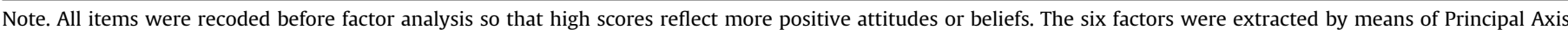
Factoring. A rotated factor solution is displayed using oblique rotation (Direct Oblimin). Factor loadings smaller than .30 have been omitted from the table.

expected that the DCN is less vulnerable to response bias than other connectedness to nature self-report measures (Brügger et al., 2011).

The DCN consists of 40 items (see Brügger et al., 2011). Of these 40 items, 26 consist of behavioral self-reports, such as "I help snails cross the street." The remaining items consist of evaluative statements tapping into a person's appraisal of nature, such as "I enjoy gardening." Two different response formats are used: a yes/no format, and a 5-point response format ranging from never to very often. Across all items, and all participants, there were 210 (i.e., 2.54\%) missing responses.

The scale calibration was identical to the procedure adopted by Brügger et al. (2011). The Rasch analysis was performed with the Winsteps software (Linacre, 2012b). All items fitted the model sufficiently with $M S$-values $\leq 1.23$. Connectedness to nature was estimated with a reliability of .85 . The average connectedness to nature was $M=-0.14$ logits ( $S D=0.97$; range $-2.47-2.17$ ). For an acceptable 12 (i.e., 5.8\%) out of the 207 participants, the model prediction did not fit the data as indicated by $t$-values of $t \geq 1.96$.

As expected with a largely behavioral connectedness to nature measure, our participants' responses were not affected by the type of lighting they evaluated: DCN scores of participants in the daylight $(M=0.05, S D=0.98)$, the daylight simulator $(M=-0.27$, $S D=1.01)$, and the fluorescent tube condition $(M=-0.21$,
$S D=0.91)$ did not differ statistically, with $F(2,204)=2.2, p=.12$, and $\eta^{2}=.02$.

\subsection{Results $\mathcal{E}$ discussion}

For each light source, mean scores for perceived naturalness, ecological impact, general attitude, and health, concentration and aesthetical beliefs, as well as their standard error of estimate are reported in Table 4 . There were no outliers, and all variables, except general attitude, had a normal distribution. A square root transformation resolved the normality issue, but since original and transformed attitude scores yielded highly similar results, the former are reported because of ease of interpretation of scale values. All assumptions behind ANOVA and regression analysis were met.

First, we confirmed whether differences in the perceived naturalness of the three light sources were consistent with the results of Study 1. For this purpose, we performed a one-way ANOVA with light type as the independent, and perceived naturalness as the dependent variable. As expected, the three types of light differed in perceived naturalness, with $F(2,204)=91.7, p<.01$, and $\eta^{2}=.39$. Additional pairwise comparisons (LSD) confirmed the results of Study 1: Daylight was perceived as more natural than light emitted

Table 3

Correlations between general attitude and lighting beliefs across the three lighting sources in Study 4 .

\begin{tabular}{|c|c|c|c|c|c|c|}
\hline & Naturalness & Eco-impact & Concentration & Health & Aesthetics & General attitude \\
\hline Naturalness & $.92^{\mathrm{a}}$ & $.53^{* *}$ & $.46^{* *}$ & $.65^{* *}$ & $.66^{* *}$ & $.30^{* *}$ \\
\hline Eco-impact & & $.89^{\mathrm{a}}$ & $.19^{* *}$ & $.36^{* *}$ & $.29^{* *}$ & .06 \\
\hline Concentration & & & $.89^{\mathrm{a}}$ & $.63^{* *}$ & $.51^{* *}$ & $.63^{* *}$ \\
\hline Health & & & & $.87^{\mathrm{a}}$ & $.60^{* *}$ & $.54^{* *}$ \\
\hline Aesthetics & & & & & $.78^{\mathrm{a}}$ & $.41^{* *}$ \\
\hline General attitude & & & & & & $.92^{\mathrm{a}}$ \\
\hline
\end{tabular}

${ }^{* *} p<.01$.

a The diagonal shows reliability (Cronbach's $\alpha$ ) estimates. 
Table 4

Means and standard errors of estimate of general attitude and lighting beliefs for the three different light sources in Study 4.

\begin{tabular}{|c|c|c|c|c|c|c|}
\hline & Naturalness & Eco-impact & Concentration & Health & Aesthetics & General Attitude \\
\hline Daylight & $1.48(.14)$ & $2.1(.13)$ & $0.83(.12)^{\mathrm{a}}$ & $0.85(.11)^{\mathrm{a}}$ & $0.81(.10)^{\mathrm{a}}$ & $1.17(.14)^{\mathrm{a}}$ \\
\hline Daylight simulator & $0.43(.15)$ & $0.9(.13)^{\mathrm{a}}$ & $0.80(.13)^{\mathrm{a}}$ & $0.70(.11)^{\mathrm{a}}$ & $0.91(.10)^{\mathrm{a}}$ & $1.55(.14)^{\mathrm{a}}$ \\
\hline Fluorescent & $-0.78(.14)$ & $0.7(.13)^{\mathrm{a}}$ & $0.26(.12)$ & $0.00(.11)$ & $-0.19(.10)$ & $1.23(.13)^{a}$ \\
\hline
\end{tabular}

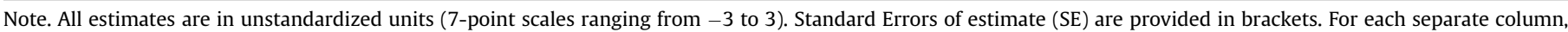
estimates that share superscript do not differ significantly with $p<.05$.

by the daylight simulator $(p<.01)$, which in turn was significantly more natural than light emitted by fluorescent (TL) tubes $(p<.01$; see Table 4 for means and standard errors of estimate).

Second, we conducted three mediation analyses-one for each comparison between two light sources-using dummy coding: daylight (coded with a 1) versus TL lighting (coded with a 0 ), daylight simulation (coded with a 1 ) versus TL lighting (coded with a 0 ), and daylight (coded with a 1 ) versus daylight simulation (coded with a 0 ). The purpose of these analyses was twofold. First, we tested whether differences in the perceived naturalness of two light sources also translated into different attitudes toward their application in an office environment. Second, we investigated whether people's beliefs with respect to the effects of more natural light on health, concentration, and the aesthetics of a room could explain part of the anticipated naturalness-attitude relationship.

In each analysis, we included general attitude as the dependent variable, and beliefs regarding health, concentration, and aesthetics as mediators. Ecological impact was included as a control mediator. The analyses were performed using the PROCESS custom dialog for SPSS as developed by Hayes (2013). The 95\% confidence intervals for indirect effects were estimated through 1000 bootstrap samples (bias corrected). The results are reported in three figures: one for the daylight versus fluorescent lighting (Fig. 1), one for the daylight

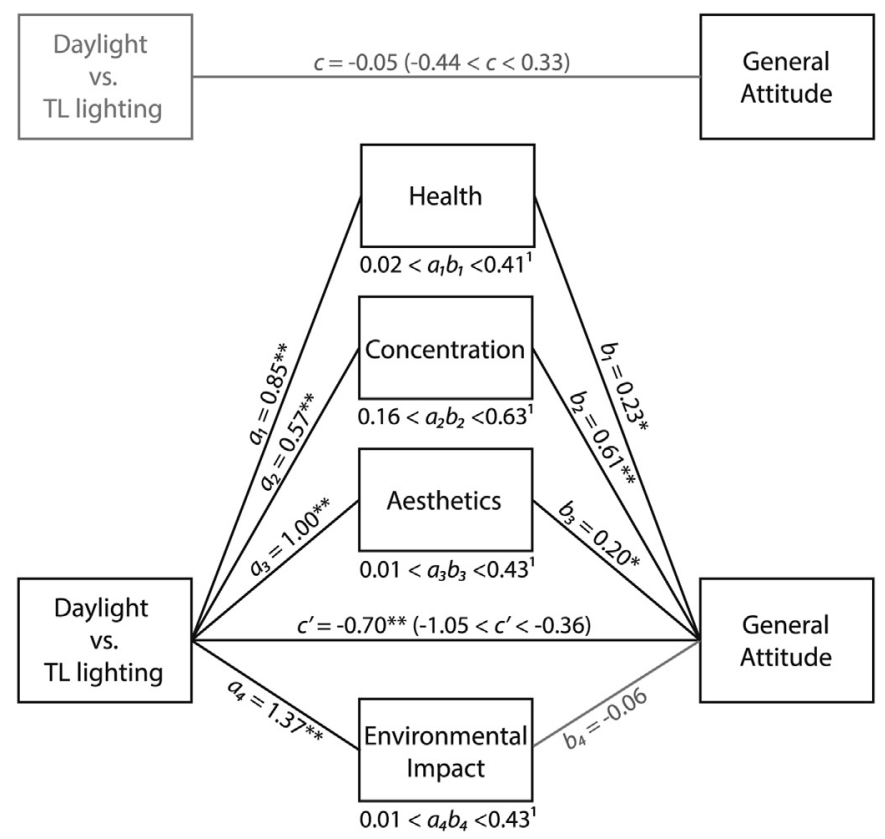

Fig. 1. Tests of mediation of the difference in people's general attitude toward the application of daylight (coded with a 1) and fluorescent lighting (coded with a 0 ) in the office by health, concentration, and aesthetical beliefs. Ecological impact was included as a control variable. All estimates are in unstandardized units (7-point scale ranging from -3 to 3 ). The $c$-path explained $R^{2}=0.1 \%$ of the variance in general attitudes, the $b$-paths and $c^{\prime}$-path together $51.6 \%$. The variance accounted for by the a-paths were $R^{2}=19.2 \%$ for health, $7.6 \%$ for concentration, $23.0 \%$ for aesthetics, and $29.4 \%$ for environmental impact. All confidence intervals are 95\%. ${ }^{1}$ Based on 1000 bootstrap samples (bias corrected). Gray lines indicate statistically non-significant paths. ${ }^{*} p<.05 .{ }^{* *} p<.01$. simulator versus fluorescent lighting (Fig. 2), and one for the daylight versus daylight simulator comparison (Fig. 3). Below a summary of the main findings is given. Since mediators were not experimentally manipulated these results should be interpreted with care (e.g., Bullock, Green, \& Ha, 2010).

Against our expectations, none of the mediation analyses showed a statistically significant total effect (i.e., the c-paths in Figs. 1-3). In other words, contrary to the natural preference hypothesis, similar application attitudes were expressed for all three types of lighting. However, we found the lighting beliefs-health, concentration, and to a lesser extent aesthetics - to mediate positively the naturalness-attitude relationship, at least when comparing either daylight or daylight simulation with fluorescent lighting (as indicated by the 95\% confidence intervals of the indirect effects; see Figs. 1-3). However, relative difference in the explanatory power of these mediators should be interpreted with care due to the high correlations between mediators (see Table 3).

Daylight and daylight simulation, thus, were believed to have more positive effects on health and concentration than fluorescent lighting (i.e., the a-paths in Figs. 1 and 2). In turn, stronger beliefs with regard to a light source's effect on health and concentration were associated with more positive attitudes toward the application of a light source in the office (i.e., the b-paths in Figs. 1-3). These results are consistent with the hypothesis that instrumental beliefs motivate the natural preference. It is thus rather surprising that regardless of this positive mediation, no statistically significant differences were found between the three light sources with respect to application attitudes, especially when daylight was contrasted against fluorescent lighting.

Since non-significant total effects and positive mediation occur together, the statistically significant direct effects may provide an explanation (i.e., the $c^{\prime}$-path in Fig. 1). Reflecting the attitude difference between daylight and fluorescent lighting but with the effects of the mediators partialled out, this direct effect suggests that another unforeseen variable may mediate the naturalnessattitude relationship in the opposite way; largely nullifying the positive indirect paths through the instrumental beliefs (i.e., competitive mediation; see Zhao, Lynch Jr., \& Chen, 2010).

As a final analysis, we correlated participants' connectedness to nature with perceived naturalness, general attitude, and each of the four lighting beliefs. These correlations were estimated separately for the three types of light. Connectedness to nature was normally distributed, and there were no outliers. No significant correlations were observed with any of the lighting appraisals. The highest-but non-significant correlation-was observed with general attitude toward fluorescent lighting $(r=.21$, and $p=.07)$. This positive correlation is inconsistent with an ideational basis for the natural preference. Instead, one would expect the opposite: the more a person is part of nature, the more aversive he or she should be toward fluorescent light sources.

\section{General discussion}

Taken together, the four studies demonstrate the plausibility of our hypothesis that the natural preference is also operative in the domain of light. Study 1 demonstrated that people can apply the 
term natural in a meaningful and consistent manner when differentiating between light emitted by various daylight and electrical sources. Taken together, Studies 2 and 3 demonstrated that people do not only regard daylight as more natural than light emitted by electrical sources, but that they also prefer it. With respect to people's motives behind the natural preference in the lighting domain, Study 4 suggested positive associations between perceived naturalness and people's beliefs with respect to light's beneficial effects on health, concentration, and the aesthetics of a room; associations that, in turn, positively affected their attitude toward the use of natural light in an office environment. In contrast, we did not find an individual's connectedness to nature to correlate with his or her naturalness-related lighting appraisals. We expected such correlations when moral or ideational considerations motivate the natural preference.

The results of Study 1 largely corroborate previous studies on the natural preference in the domains of food and medication (e.g., Rozin, 2005, 2006); demonstrating that what people perceive to be natural depends on both the source and the subsequent physical transformation of the natural substance. First, light emitted by the sun, however it entered the building, was always regarded as more natural than electrical lighting, except for light emitted by a daylight simulator. Second, we found the perceived naturalness of sunlight to diminish when it passes through or is reflected by different media (e.g., blinded glass or mirrors).

Study 1 revealed differences between electrical light sources as well. Light emitted by an incandescent light bulb, for example, was regarded as more natural than that emitted by LEDs and fluorescent tubes. Although the present studies cannot explain these differences, they are perhaps related to people's familiarity with the incandescent bulb, to the color temperature of the light it emits, or

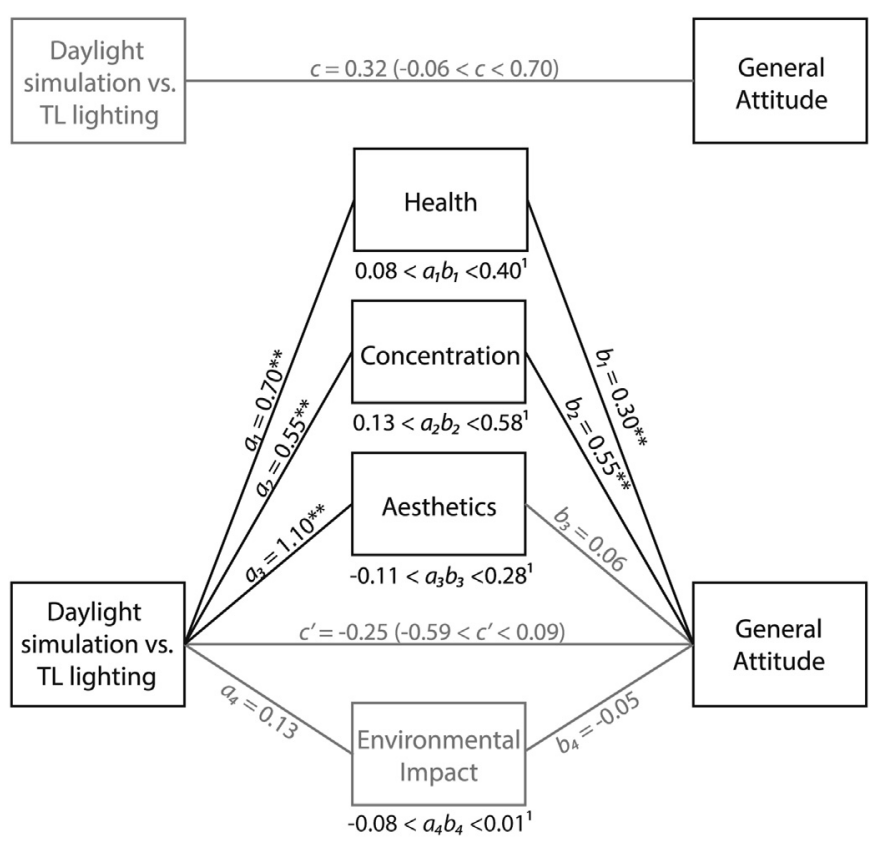

Fig. 2. Tests of mediation of the difference in people's general attitude toward the application of daylight simulation (coded with a 1) and fluorescent lighting (coded with a 0 ) in the office by health, concentration, and aesthetical beliefs. Ecological impact was included as a control variable. All estimates are in unstandardized units (7point scale ranging from -3 to 3 ). The $c$-path explained $R^{2}=2.1 \%$ of the variance in general attitudes, the $b$-paths and $c^{\prime}$-path together $45.6 \%$. The variance accounted for by the $a$-paths were $R^{2}=13.4 \%$ for health, $7.4 \%$ for concentration, $3.0 \%$ for aesthetics, and $0.3 \%$ for environmental impact. All confidence intervals are $95 \% .{ }^{1}$ Based on 1000 bootstrap samples (bias corrected). Gray lines indicate statistically non-significant paths. ${ }^{*} p<.05 .{ }^{* *} p<.01$.

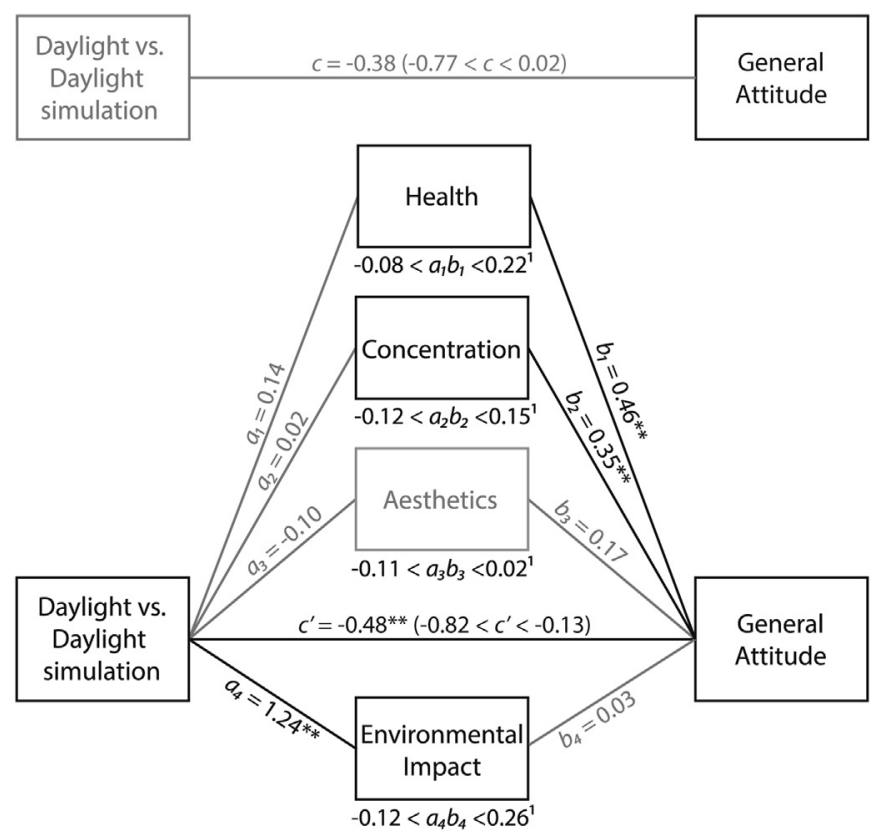

Fig. 3. Tests of mediation of the difference in people's general attitude toward the application of daylight (coded with a 1) and daylight simulation (coded with a 0 ) in the office by health, concentration, and aesthetical beliefs. All estimates are in unstandardized units (7-point scale ranging from -3 to 3 ). The c-path explained $R^{2}=2.6 \%$ of the variance in general attitudes, the $b$-paths and $c^{\prime}$-path together $51.7 \%$. The variance accounted for by the a-paths were $R^{2}=0.6 \%$ for health, $<0.1 \%$ for concentration, $0.4 \%$ for aesthetics, and $30.4 \%$ for environmental impact. All confidence intervals are $95 \%$. ${ }^{1}$ Based on 1000 bootstrap samples (bias corrected). Gray lines indicate statistically non-significant paths. ${ }^{*} p<.05 .{ }^{* *} p<.01$.

simply to it being such iconic light source. One interesting extension of our Study 1 would be to include light from candles and open fires. Based on the present findings, we expect these to fall somewhere between sunlight and the incandescent bulb on our perceived naturalness scale.

Against our expectations, the results of Study 2 did not confirm the natural preference hypothesis: There was no statistically significant preference for the room lit by a daylight harvester over the room lit by a daylight simulator. Based on our participants' selfreported choice motives, we realized that some participants did not understand the concept of daylight harvesting, and that the artificial option had a considerable instrumental benefit over the natural option in terms of providing light during evenings and nights. When we controlled for these possible confounds in Study 3, there was a clear and statistically significant preference for the more natural option.

We aimed to replicate the results from Study 1 and Study 3 using a different paradigm in Study 4. Rather than a forced-choice decision making paradigm, this study involved a survey in which three different light sources were evaluated in a between-subject design. Consistent with the findings of Study 1, daylight through a skylight was perceived as more natural than either light emitted by a daylight simulator or light from fluorescent tubes. Contrary to our expectations, and contrary to Study 3, we did not find statistically significant differences between any of these light sources with respect to people's attitudes toward the application of these light sources in an office environment, despite perceived naturalness, lighting beliefs, and application attitudes all being correlated.

We tried to unravel some of these complexities using mediation analysis. The results provided preliminary confirmation of previous research in that more natural light-both daylight and simulated daylight-were perceived as better for one's health and 
concentration than fluorescent lighting (e.g., Veitch et al., 1993; also Veitch \& Gifford, 1996). Interestingly, no statistically significant differences were found between daylight and simulated daylight in these respects. In other words, simulated daylight was regarded to be as healthy, as good for one's concentration, and as aesthetically pleasing as natural daylight.

In turn, we found the strength of such beliefs to be positively correlated with people's attitudes toward the use of a light source in an office environment; thus supporting the natural preference hypothesis. With these instrumental beliefs positively mediating the naturalness-preference relationship, it is surprising that we did not observe an attitude difference between the three types of lighting. However, the statistically significant direct effects suggest that in the formation of the attitude any perceived instrumental benefits of daylight over fluorescent light may have been nullified by another unforeseen mediator. One interesting question than presents itself: What would be a likely candidate for this competitive mediator?

We believe that Study 2 may be informative in this manner. It seems reasonable to postulate that control over illuminance levels, especially during evenings and cloudy days, gives electrical lighting a benefit over natural daylight in an office environment; one that perhaps outweighs the positive health and concentration effects that people associate with the latter. In support of this tentative explanation, statistically significant direct effects were only observed when comparing daylight with the two electrical light sources, but not when comparing the daylight simulator with fluorescent lighting. Being both electrical light sources, functional differences in control over the light should be smaller between daylight simulation and fluorescent lighting. More research is needed to substantiate these speculations.

Although Study 4 suggests that beliefs regarding light's effect on health and concentration motivate the natural preference, we did not succeed in demonstrating a moral or ideational motive. Although such ideational motives have traditionally been related to Wilson's (1984) notion of biophilia (Rozin et al., 2004), we found individuals' connectedness to nature to be related neither to a preference for natural, nor to an aversion toward artificial light. Since this is, to our knowledge, the first time that ideational motives have been explored more directly through individual differences in connectedness to nature, more research is needed to substantiate the validity of this approach.

There were two limitations to the present studies. First, we relied solely on written descriptions of light (i.e., vignettes), rather than on direct experience with it. Future research should investigate whether the natural preference still exists when people are actually subjected to light from different natural and electrical light sources. Second, we focused exclusively on people's appraisal of light. It would thus be interesting to test whether perceptions of naturalness also affect the behavioral or cognitive outcomes of being exposed to different types of light. Based on the present studies we can only speculate whether a preference for more natural light can be demonstrated in such conditions.

Despite these limitations, the four studies provide tentative evidence that the human tendency to prefer natural substances over their synthetic counterparts is also operative in the domain of light. At the same time, our research suggests that any naturalnessrelated preferences, which we demonstrated to be related to beliefs regarding the positive health and concentration effects of natural light, may be nullified if the light of the sun is not sufficiently under our control. As such, our results are of potential interest to light designers and manufacturers interested in (simulated) daylight solutions, and to researchers interested in the psychological effects of light on people.

\section{Acknowledgments}

This research is affiliated to the Intelligent Lighting Institute at Eindhoven University of Technology, Eindhoven, The Netherlands. Some of the studies were part of the ENSURE initiative, in which Philips and Eindhoven University of Technology collaborated in research on intelligent lighting solutions. We thank the Dutch Ministry of Economic Affairs for their financial support (KennisWerkersRegeling; KWR). We thank Koen Olijve and Raymond Smeets for their assistance in running the experiments. Parts of the present paper were presented at the Experiencing Light 2012 conference, November 12-13, 2012, Eindhoven, The Netherlands.

\section{References}

Beckstead, J. W., \& Boyce, P. R. (1992). Structural equation modelling in lighting research: An application to residential acceptance of new fluorescent lighting. Lighting Research \& Technology, 24, 189-201.

van Bommel, W. J. M. (2006). Non-visual biological effect of lighting and the practical meaning for lighting for work. Applied Ergonomics, 37, 461-466.

Bond, T. G., \& Fox, C. M. (2007). Applying the Rasch model: Fundamental measurement in the human sciences (2nd ed.). Mahwah, NJ: Erlbaum.

Boyce, P. R. (2012). Review: The impact of light in buildings on human health. Indoor and Built Environment, 19, 8-20.

Brügger, A., Kaiser, F. G., \& Roczen, N. (2011). One for all? Connectedness to nature, inclusion of nature, environmental identity, and implicit association with nature. European Psychologist, 16, 324-333.

Bullock, J. G., Green, D. P., \& Ha, S. E. (2010). Yes, but what's the mechanism? (Don't expect an easy answer). Journal of Personality and Social Psychology, 98, 550-558.

Carter, S. (2007). Rise and shine: Sunlight, technology, and health. Berg: Oxford.

Davis, J. L., Green, J. D., \& Reed, A. (2009). Interdependence with the environment: Commitment, interconnectedness, and environmental behavior. Journal of Environmental Psychology, 29, 173-180.

DiBonaventura, M., \& Chapman, G. B. (2008). Do decision biases predict bad decisions? Omission bias, naturalness bias, and influenza vaccination. Medical Decision Making, 28, 532-539.

Hayes, A. F. (2013). Introduction to mediation, moderation, and conditional process analysis: A regression-based approach. New York: Guilford Press.

Hollands Diep. (Dec 2009/January 2010). Interview with Ingo Maurer (pp. 158-159).

Kaiser, F. G., Byrka, K., \& Hartig, T. (2010). Reviving Campbell's paradigm for attitude research. Personality and Social Psychology Review, 14, 351-367.

Kellert, S. R., \& Wilson, E. O. (Eds.). (1993). The biophilia hypothesis. Washington, DC: Island Press.

de Kort, Y. A. W., \& Smolders, K. C. H. J. (2010). Effects of dynamic lighting on office workers: First-year results of a longitudinal field study. Lighting Research \& Technology, 42, 345-360.

Li, M., \& Chapman, G. B. (2012). Why do people like natural? Instrumental and ideational bases for the naturalness preference. Journal of Applied Social Psychology, 42, 2859-2878.

Linacre, J. M. (2002). Construction of measures from many-facet data. Journal of Applied Measurement, 3, 486-512.

Linacre, J. M. (2012a). Facets (Version 3.70.0) [Computer software]. Beaverton, Oregon: Winsteps.com.

Linacre, J. M. (2012b). Winsteps (Version 3.75.0) [Computer Software]. Beaverton, Oregon: Winsteps.com.

Linacre, J. M. (2012c). Facets computer program for many-facet Rasch measurement, version 3.70.0. Beaverton, Oregon: Winsteps.com.

McColl, S. L., \& Veitch, J. A. (2001). Full-spectrum fluorescent lighting: A review of its effects on physiology and health. Psychological Medicine, 31, 949-964.

Rozin, P. (2005). The meaning of "natural": Process more important than content Psychological Science, 16, 652-658.

Rozin, P. (2006). Natural judgments by lay Americans: Process dominates content in judgments of food or water acceptability and naturalness. Judgment and Decision Making, 1, 91-97.

Rozin, P., Spranca, M., Krieger, Z., Neuhaus, R., Surillo, D., Swerdlin, A., et al. (2004). Preference for natural: Instrumental and ideational/moral motivations, and the contrast between foods and medicines. Appetite, 43, 147-154.

Scholten, L., \& Midden, C. (1997). Milieubelasting van verpakkingen: Effecten van de 'natuurlijkheidsbias' op consumentenoordelen [The environmental impact of packaging: Effects of judgemental bias towards natural packaging materials on consumer evaluations]. Milieu, 4, 167-174.

Schultz, P. W. (2001). The structure of environmental concern: Concern for the self, other people, and the biosphere. Journal of Environmental Psychology, 21, 327339.

Schultz, P. W., Shriver, C., Tabanico, J., \& Khazian, A. (2004). Implicit connections with nature. Journal of Environmental Psychology, 24, 31-42.

Veitch, J. A., \& Gifford, R. (1996). Assessing beliefs about lighting effects on health, performance, mood, and social behavior. Environment and Behavior, 28, 446-470.

Veitch, J. A., Hine, D. W., \& Gifford, R. (1993). End users' knowledge, preferences, and beliefs for lighting. Journal of Interior Design, 19(2), 15-26. 
Veitch, J. A., \& McColl, S. L. (2001). A critical examination of perceptual and cognitive effects attributed to full-spectrum fluorescent lighting. Ergonomics, 44, 255279.

Wilson, E. O. (1984). Biophilia. Cambridge: Harvard University Press.

Wright, B. D., \& Linacre, J. M. (1994). Reasonable mean-square fit values. Rasch Measurement Transactions, 8, 370.
Wurtman, R. J. (1975). The effects of light on the human body. Scientific American, 233(1), 69-77.

Wurtman, R. J., \& Neer, R. M. (1970). Good light and bad. New England Journal of Medicine, 282, 394-395.

Zhao, X., Lynch, J. G., Jr., \& Chen, Q. (2010). Reconsidering Baron and Kenny: Myths and truths about mediation analysis. Journal of Consumer Research, 37, 197-206. 